\title{
JUURNAL.RU
}

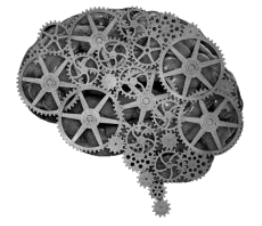

COMPANY GROUP "INTELLEKT"

\author{
Гавриков А.А. \\ Омский автобронетанковый инженерный институт \\ Омск, Россия
}

doi: 10.18411/lj2016-6-1-06

\section{Психологическая готовность курсантов к проектной деятельности}

Особенностью проектной деятельности военного инженера выступает то, что она, как и ее результаты, инженерные исследования, в отличие от теоретических исследований в технических науках, непосредственно вплетены в содержание военно-профессиональной деятельности военного инженера.

Анализ психолого-педагогической литературы, посвященной разработке теории проектной деятельности (Т. Г. Белова [2] и др.), свидетельствует, что проектная деятельность в ее прикладном понимании не является онтологически заданной для педагогической сферы, как, например, воспитание или обучение. Однако значительный интерес, который проявляла и проявляет к проектной деятельности педагогическая наука, обусловлен потенциальными возможностями проектной деятельности развивать своего субъекта, оказывать влияние на его личность. Так, организация проектной деятельности курсантов в рамках научно-исследовательской работы военно-инженерного вуза требует развития у них соответствующего интереса и мотивации, на что, например, раскрывая психолого-педагогические факторы успешности научноисследовательской работы студентов, обращают внимание Л. Ф. Авдеева[1], Д. С. Терехина [6]. Результаты проведенного Л. Ф. Авдеевой корреляционного анализа позволяют отвести мотивации научно-исследовательской работы обучающихся ведущее место в определении ее эффективности, причем как в достижении научного результата, так и в развитии субъекта профессиональной 
деятельности [1]. Мощным средством мотивации обучающихся в выборе для проекта темы и проблемы, руководителя и формы участия в проекте Д. С. Терехина считает наличие информационного поля научно-исследовательской деятельности [6].

Исследования в области военной психологии и педагогики (О.Ю. Ефремов[3] и др.) также указывают на определяющую роль мотивов военнопрофессиональной деятельности в целом, их влияние на любые стороны процесса развития человека в военной профессии. В нашем случае это предполагает выбор курсантами вооружения как предмета будущей профессиональной деятельности, и, как следствие выбора, осознанное развитие своих профессиональных навыков применения вооружения в процессе инженерно-эксплуатационной подготовки.

Так как в структуре проектной деятельности курсантов важное, на наш взгляд, место занимают еe технологии, то опора на выявленную психологическую структуру требует обратить внимание на методологическую и операциональную подготовку курсантов, их обучение и формирование у них соответствующего опыта. В этом утверждении мы полностью согласны с А. В. Леонтовичем [5].Формирование профессионального опыта, в отличие от бытового, как следует из работФ. С. Исмагиловой [4]- это не пробы и ошибки, а использование обоснованного способа действий при условии правильной рефлексии, анализа и интериоризации опыта других субъектов профессиональной деятельности.

Рефлексия опыта проектной деятельности предполагает эмоциональную оценку, т. Е. более или менее устойчивое эмоциональное отношение курсанта к проектной форме работы. В дальнейшем она обусловит выбор проектной или другой формы выполнения профессиональных задач, даже если проектная форма будет заранее более эффективной.

Эмоциональная оценка собственного опыта проектной деятельности оказалась негативной практически у половины испытуемых (рисунок 1). 
Отметим, что в число испытуемых вошли выпускники военно-инженерного вуза, у которых ранее было выявлено наличие опыта проектной деятельности.49,4\% курсантов (36 человек) в процессе опроса заявили, что испытывали от участия в проектах только отрицательные или в основном отрицательные эмоции. Еще 20,5\% (15 человек) не могли определиться, т. Е. не имели четкой эмоциональной оценки. Наконец, только $30,1 \%$ обладали преимущественно положительной эмоциональной оценкой своего опыта проектной деятельности.

В то же время мы посчитали достаточно достоверной оценку психологической готовности респондентов к проектной деятельности. Ориентируясь на устойчивое состояние психики курсанта, мы использовали для диагностики метод самооценки и предложили курсантам определить свою готовность к проектной деятельности (рисунок 1).

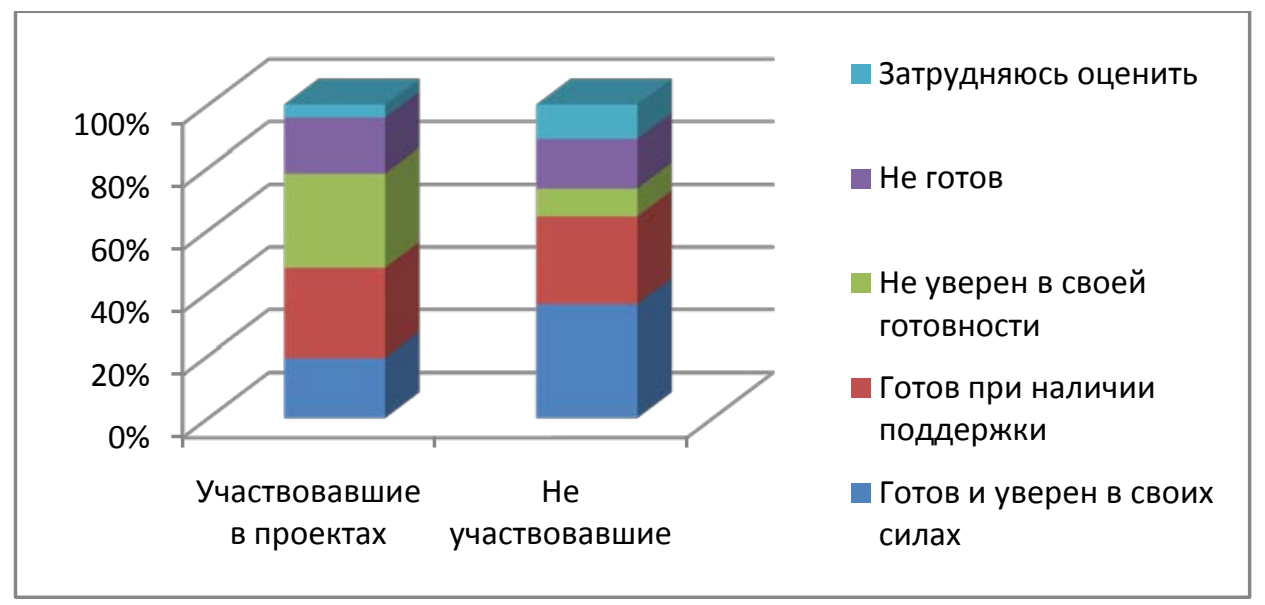

Рисунок 1. Результаты выявления самооценки курсантами психологической готовности к проектной деятельности ( $\Sigma=73$ и 146)

Обращает на себя внимание тот факт, что курсанты, ранее принимавшие участие в проектной деятельности, оценивают собственную готовность более скептически. Обратимся к данным, представленным в диаграмме (рисунок 1). Если в первом случае полную готовность к проектной деятельности заявили 19,1\% участников эксперимента, то во втором их больше почти вдвое - 36,3\%. Нам кажется, что такая уверенность вряд ли имеет под собой прочную основу. И наоборот, если среди курсантов, ранее принимавших участие в проектной деятельности, людей, не уверенных в своих силах - 30,1\%, то среди второй 
группы их только 8,9\%. Остальные категории ответов численно выражены приблизительно в равных долях.

Военно-профессиональный компонент отражает в целом профессиональную подготовку будущих военных инженеров, которая имеет множество граней и составляющих. Изучение и оценка его качеств не принесли каких-либо неожиданностей, а полученный результат совпал с внешней экспертной оценкой образовательного процесса ОАБИИ, о которой было сказано выше. В дальнейшем при проведении апробации разработанной нами модели мы рассчитывали на обратную связь, при которой общее развитие проектной компетентности будущих военных инженеров будет способствовать развитию их военно-инженерной подготовки, технического кругозора, эрудиции и технической культуры.

Анализ результатов выполненной диагностики развития качеств проектной компетентности будущих военных инженеров позволяет сделать несколько обобщений.

Во-первых, в существующей практике качества проектной деятельности развиваются весьма неравномерно. Так, при достаточно высокой общей профессиональной подготовке курсантов, у них оказались слабо развитыми другие элементы структуры проектной деятельности: мотивы, способы действий, знания, умения и навыки. В отсутствие специально организованной проектной деятельности не формируется ее опыт, или этот опыт зачастую носит негативный характер.

Во-вторых, проектная деятельность не проецируется на все сферы профессиональной деятельности будущего военного инженера, что существенно ограничивает ее применение в дальнейшем, в процессе службы в офицерских должностях.

В третьих, в исследуемой практике не применяются какие-либо специальные решения, позволяющие организовать развитие проектной компетентности с точки зрения научных основ проектной деятельности. В 
условиях стихийной или научно-необоснованной проектной деятельности курсантов происходит не развитие, а регресс интересующего нас качества, прежде всего, за счет отрицательной эмоциональной окраски, негативного опыта, психологической неуверенности и неготовности к проектной деятельности.

На основе данных обобщений можно сделать вывод о существовании в исследуемой практике противоречия между современными требованиями военно-профессиональной деятельности к своему субъекту и развитием проектной компетентности будущих военных инженеров в образовательном процессе военно-инженерного вуза. 


\section{Литература:}

1. Авдеева, Л. Ф. Психолого-педагогические факторы успешности научноисследовательской работы студентов: автореф. дис. ...канд. пед. наук: 13.00.01 / Авдеева Людмила Федоровна. - Л., 1984. - 16 с.

2. Белова, Т. Г. Исследовательская и проектная деятельность учащихся в современном образовании / Т. Г. Белова // Известия Российского государственного педагогического университета им. А. И. Герцена. - 2008. - № 35. - С. 30-35.

3. Ефремов, О. Ю. Военная педагогика; учебник для вузов / под ред. О. Ю. Ефремова. - СПб.: Питер, 2008. - 640 с.

4. Исмагилова, Ф. С. Профессиональный опыт специалистов и управление им в условиях формирования рыночной экономики: автореф. дис. ...д-ра психол.наук: 19.00.03 / Исмагилова ФайрузаСалихджановна.- М., 2000.-41 c.

5. Леонтович, А. В. Исследовательская деятельность учащихся: сб. статей / А. В. Леонтович // Библиотека журнала «Исследовательская работа школьников». - М., 2006. - 114 с.

6. Терехина, Д. С. Научно-исследовательская деятельность студентов как объект социального управления в современном российском вузе: автореф. дис. ...канд. социол. наук: 22.00.08 / Терехина Диана Сергеевна. - М., 2012. $-24 \mathrm{c}$. 